\title{
Commentary: The fate of pediatric cardiac palliations: Beyond the convergence
}

\author{
Kyle D. Hope, MD, ${ }^{a}$ Mohan M. John, MBBS, ${ }^{b}$ and \\ Iki Adachi, MD
}

...Two roads diverged in a wood, and I-

I took the one less traveled by,

And that has made all the difference.

\section{—Robert Frost, "The Road Not Taken"}

In this issue, Lin and colleagues ${ }^{1}$ report on long-term outcomes of neonatal heart transplantation at their center. Their work is a welcome addition, as there are limited center-level data on neonatal heart transplantation, and most published data arise from a single center that has been pioneering in this topic (Loma Linda University). ${ }^{2}$ The current work by Lin and colleagues reinforces the message championed by the Loma Linda group that neonatal heart transplantation represents an acceptable palliation for congenital heart disease and cardiomyopathy, with Lin and colleagues ${ }^{1}$ reporting a 20 -year post-transplant survival rate of $60 \%$, mirroring the results of the Loma Linda cohort. ${ }^{2}$ This additional report, while reinforcing the larger datasets of Loma Linda and the International Society for Heart and Lung Transplantation Registry, ${ }^{3}$ further emphasizes the fact that neonates undergoing heart transplantation have among the best long-term outcomes of any solid-organ transplant population.

This study, however, also begs the question: with improving survival after single-ventricle palliation in the setting of a severely limited neonatal donor pool, what is the role of neonatal heart transplant in the current era?

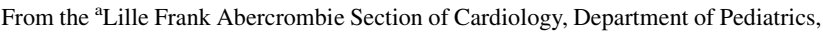
and ${ }^{\mathrm{b} C}$ Congenital Heart Surgery, Michael E. DeBakey Department of Surgery, Texas Children's Hospital, Baylor College of Medicine, Houston, Tex.

Disclosures: Dr Adachi reported consultant/proctor for Berlin Heart, Inc, Medtronic, Inc, Abbott, Inc, Jarvik Inc, and BiVACOR Inc. All other authors reported no conflicts of interest.

The Journal policy requires editors and reviewers to disclose conflicts of interest and to decline handling or reviewing manuscripts for which they may have a conflict of interest. The editors and reviewers of this article have no conflicts of interest.

Drs Hope and John contributed equally to this article.

Received for publication April 3, 2021; revisions received April 3, 2021; accepted for publication April 6, 2021; available ahead of print April 16, 2021.

Address for reprints: Iki Adachi, MD, Congenital Heart Surgery, Michael E. DeBakey Department of Surgery, Texas Children's Hospital, Baylor College of Medicine, 6651 Main St, Houston, TX 77030 (E-mail: iadachi@bcm.edu).

J Thorac Cardiovasc Surg 2021;162:1373-4

$0022-5223 / \$ 36.00$

Copyright (C) 2021 by The American Association for Thoracic Surgery

https://doi.org/10.1016/j.jtcvs.2021.04.016

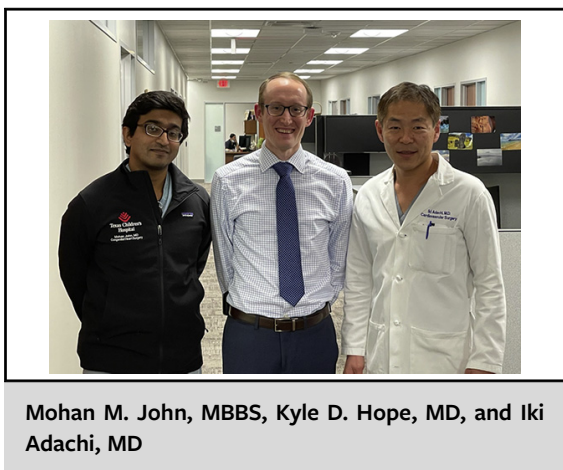

CENTRAL MESSAGE

Neonatal heart transplantation is associated with acceptable longterm survival. Pursuing transplantation in poor candidates for single-ventricle palliation may enhance survival in at-risk

neonates.

Both this study ${ }^{1}$ and the data from Loma Linda ${ }^{2}$ illustrate decreasing numbers of neonates undergoing primary transplantation with the refinement of single-ventricle palliations. The authors also describe a significant number of patients who were listed as neonates but received their transplant as infants, reflecting the increased waitlist times. The "road was less traveled" even in the previous era, where there was less shortage in organ supply. The challenge remains to identify when is the appropriate time to choose the primary transplant pathway. The boundary between the standard surgical and the selective transplant approaches is not a fixed but rather a moving target, as the environment (eg, surgical outcomes and organ supply) likely keeps changing. One thing that is certain: there is a subset of neonates that definitely requires primary transplant pathway but is unlikely to tolerate the expected longer waitlist time. The recent trend in the uses of mechanical circulatory assistance ${ }^{4,5}$ would play an important role for such patients.

It would be worth extending the discussion beyond the selection at the first divergence. Regardless of the road chosen initially, both paths will eventually converge to form a common route leading to circulatory failure, whether the mode of failure is cardiac graft dysfunction, Fontan failure, or something else. Repeat transplantation can be considered in the case of graft failure but only with limited durability. To address the current limitation in the life expectancy of 
these patients, it would be critical to develop a strategy to lengthen the life beyond what is expected with transplantrelated options. We believe that the use of durable mechanical circulatory support as a "permanent" therapy will be the ultimate solution. ${ }^{7}$ If such an approach becomes the final common pathway of any pediatric heart disease, then the role of heart transplant will be seen reversely as a "bridge" to a permanent device, which would be a paradigm shift. Given the maturation of pediatric heart failure management over the last several decades, attention should be given not only just to the initial selection but to the entire journey the child will experience. We hope that this commentary will stimulate further discussion on this matter.

\section{References}

1. Lin Y, Davis TJ, Zorrilla-Vaca A, Wojcik BM, Miyamoto SD, Everitt MD, et al. Neonatal heart transplantation outcomes: a single institutional experience. J Thorac Cardiovasc Surg. 2021;162:1361-8.
2. John MM, Razzouk AJ, Chinnock RE, Bock MJ, Kuhn MA, Martens TP, et al. Primary transplantation for congenital heart disease in the neonatal period: long-term outcomes. Ann Thorac Surg. 2019;108:1857-64.

3. Rossano JW, Singh TP, Cherikh WS, Chambers DC, Harhay MO, Hayes D Jr, et al. The International Thoracic Organ Transplant Registry of the International Society for Heart and Lung Transplantation: twenty-second pediatric heart transplantation report-2019; focus theme: donor and recipient size match. J Heart Lung Transplant. 2019;38:1028-41.

4. Philip J, Powers E, Machado D, Colon DL, Gupta D, Shih R, et al. Pulsatile ventricular assist device as a bridge to transplant for the early high-risk single-ventricle physiology. J Thorac Cardiovasc Surg. October 6, 2020 [Epub ahead of print].

5. Merritt TC, Montgomery BK, Gazit AZ, Carvajal HG, Shepard M, Mehegan M, et al. Evolution of ventricular assist device support strategies in 18 consecutive children with single ventricle physiology: a single center experience. Presented at: Annual Meeting of the Society of Thoracic Surgeons; January 29, 2021.

6. Dipchand AI, Edwards LB, Kucheryavaya AY, Benden C, Dobbels F, Levvey BJ, et al. The Registry of the International Society for Heart and Lung Transplantation: seventeenth official pediatric heart transplantation report-2014; focus theme: retransplantation. J Heart Lung Transplant. 2014;33:985-95.

7. Adachi I. Pediatric ventricular assist device support as a permanent therapy: clinical reality. J Thorac Cardiovasc Surg. 2019;158:1438-41. 